\title{
O primeiro ano do ensino fundamental de nove anos: uma revisão teórica
}

\author{
Eveline Favero \\ Universidade Estadual do Oeste do Paraná - Cascavel - PR - Brasil \\ Dhyovana Guerra \\ Universidade Estadual do Oeste do Paraná - Cascavel - PR - Brasil \\ Heder Luiz Matias Mendes dos Santos \\ Universidade Estadual do Oeste do Paraná - Cascavel - PR - Brasil \\ Camila Molon Delazeri \\ Universidade Estadual do Oeste do Paraná - Cascavel - PR - Brasil
}

\section{Resumo}

O artigo revisa publicações brasileiras que tratam do tema do primeiro ano do ensino fundamental de nove anos. Foram realizadas buscas nas bases de dados SciELO - Scientific Electronic Library Online e no Portal de Periódicos da CAPES, considerando o período 2005-2015 e utilizando-se os termos: "Ensino Fundamental de Nove Anos" e "Primeiro Ano do Ensino Fundamental". A pesquisa resultou em 43 artigos na base do SCiELO e 37 no Portal de Periódicos da CAPES. Do total, 16 artigos foram selecionados para compor a análise de conteúdo, da qual resultaram três categorias temáticas: Política Educacional, Implantação do Ensino Fundamental de Nove Anos e Alfabetização e Letramento. Os resultados revelaram preocupações, especialmente, quanto ao descompasso entre a política educacional e a prática pedagógica.Embora essas questões não possam ser generalizadas, faz-se importante considerar que a ampliação do tempo de escolarização não é, necessariamente, um indicador de qualidade no ensino.

Palavras-chave: Ensino fundamental; alfabetização; desenvolvimento infantil.

\section{The first year of elementary school of nine years: a theoretical review}

\begin{abstract}
The paper reviews Brazilian publications dealing with the theme of the first year of elementary school of nine years, considering the period from 2005 to 2015. The SciELO database (Scientific Electronic Library Online) and Portal de Periódicos da CAPES database were searched from two descriptors: The nine year of basic education and the first year of elementary school. The search resulted in 43 papers in SciELO database and 37 in Portal de Periódicos da CAPES. Of the total, 16 articles were selected for the analysis of content, which comprised three thematic categories: Education Policy, Implementation of the First Year of Elementary School, Literacy and letramento. The results revealed concerns, especially about the mismatch between educational policy and educational practice. While these issues can not be generalized, it is important to consider that the extension of school time is not necessarily an indicator of educational quality.
\end{abstract}

Keywords: basic education; literacy; child development.

\section{El primer curso de la enseñanza primaria de nueve años: una revisión teórica}

\section{Resumen}

El artículo revisa publicaciones brasileñas que tratan del tema del primer curso de la enseñanza primaria de nueve años. Se realizaron búsquedas en las bases de datos SciELO - Scientific Electronic Library Online y en el Portal de Periódicos de la CAPES, considerando el período $2005-2015$ y utilizándose los términos: "Enseñanza Primaria de Nueve Años" y "Primer Curso de la Enseñanza Primaria". La investigación resultó en 43 artículos en la base del SciELO y 37 en el Portal de Periódicos de la CAPES. Del total, se seleccionaron 16 artículos para componer el análisis de contenido, de la cual resultaron tres categorías temáticas: Política Educacional, Implantación de la Enseñanza Primaria de Nueve Años y Alfabetización y Letramento. Los resultados revelaron preocupaciones, especialmente, cuanto al descompaso entre la política educacional y la práctica pedagógica. Aunque esas cuestiones no puedan ser generalizadas, se hace necesario considerar que la ampliación del tiempo de escolaridad no es, necesariamente, un indicador de calidad en la enseñanza.

Palabras clave: Enseñanza primaria; alfabetización; desarrollo infantil. 


\section{Introdução}

A infância é muitas vezes um tema esquecido ou pouco explorado na formação do pedagogo (Szymanski \& Bastos, 2011; Szymanski, Bastos, Klieman, \& Favero, 2014). No entanto, é justamente para trabalhar com essa etapa do desenvolvimento que a maioria dos pedagogos têm se inserido no mercado de trabalho. A ideia de infância, por sua vez, trata-se de uma construção histórica e social que varia de acordo com as formas de organização da sociedade e do papel exercido pela criança em determinado contexto. Portanto, a concepção de infância nem sempre foi a mesma em diferentes momentos históricos e em diferentes sociedades. Assim, a concepção atual surgiu com a sociedade capitalista urbano-industrial na medida em que foi mudando a inserção e o papel social da criança na própria sociedade (Ariès, 1978; Lugle \& Aguiar, 2009).

Embora a ideia de infância seja universalizada, de acordo com Kramer (2007), numa sociedade desigual as crianças desempenham também diferentes papéis em diferentes contextos. Desse modo, "a ideia de infância moderna foi universalizada com base em um padrão de crianças das classes médias, a partir de critérios de idade e de dependência do adulto, característicos de sua inserção no interior dessas classes" (Kramer, 2007, pp. 14-15).

Tendo em vista fatores como a violência praticada contra a criança nos dias atuais, seja pela negligência dos pais ou cuidadores, pobreza, maus tratos ou pelo trabalho infantil, alguns autores defendem a ideia deque "o reino encantado da infância teria chegado ao fim" (Kramer, 2007, p.15). Nessa direção, autores como Postman (1999), têm "denunciado" o desaparecimento da infância, problematizando questões como o acesso das crianças às informações que dizem respeito ao mundo dos adultos, por meio de recursos da tecnologia digital. Por outro lado, mesmo com as mudanças aceleradas em diferentes aspectos da vida social, teóricos defendem que a criança não pode ser resumida a aquilo que não é, cabendo aos adultos reconhecerem o que é específico da infância como a imaginação, a fantasia, a criação e a brincadeira (Kramer, 2007).

A partir do momento em que a criança passa a ser entendida como cidadã, coloca-se a infância como categoria da história e não apenas como um estágio do desenvolvimento humano. A criança também produz e reproduz a cultura através de suas brincadeiras, da ação e interação com o ambiente, sendo assim produtora e produto da história na sua tentativa de conhecer e descobrir o mundo (Benjamin, 1984).

Além de ser vista como um ser histórico e impregnado de cultura e tradição, a criança deve ser vista como pertencente a uma classe social e a uma comunidade, é sujeito social que nasce no interior de uma etnia, a qual diz respeito a um grupo social (Benjamin, 1984). Apesar de a infância ser um momento importante na vida humana, não se pode inverter ou esquecer certos valores. As crianças têm e devem ter direitos, mas os papéis não podem ser invertidos, como aponta Kramer (2007) discorrendo sobre a questão da autoridade. Quando o adulto abdica de assumir seu papel, deixando com que a criança-sujeito dite as regras, o lugar do adulto fica desocupado, o que revela uma distorção profunda no sentido da autoridade (Kramer, 2007). Desse modo, verifica-se a importância de se garantir para a criança a sua infância, e assim possibilitar o desenvolvimento saudável e o atendimento adequado das suas necessidades.

\section{A inclusão da criança de seis anos no ensino fundamental: aspectos legais}

No que diz respeito à educação escolar do infante, desde a implantação da Lei 11.274/2006 (2006) que instituiu o Ensino Fundamental (EF) de nove anos, muitas questões polêmicas têm sido levantadas, dentre as quais está o distanciamento entre a política educacional e a prática pedagógica. As mudanças legais que implicam na inclusão da criança de seis anos no primeiro ano do Ensino Fundamental têm como objetivo "oferecer maiores oportunidades de aprendizagem no período da escolarização obrigatória e assegurar que, ingressando mais cedo no sistema de ensino, as crianças prossigam nos estudos, alcançando maior nível de escolaridade" (Ministério da Educação \& Fundo Nacional de Desenvolvimento da Educação, 2004, p. 14). Considerando o exposto, verifica-se com nitidez na política a centralidade da busca pela inclusão, especialmente daquelas crianças que, por diferentes fatores sociais e econômicos, estão fora da escola com a idade de seis anos.

Todavia, uma prática de inclusão não pode estar em desacordo com as necessidades de quem se quer incluir. Nesse sentido, o Plano Nacional de Educação (Lei n. 10.172, 2001) ao prever a implantação progressiva do Ensino Fundamental de nove anos, apontou que "a inclusão das crianças de seis anos, deve se dar em consonância com a universalização na faixa etária de sete a 14 anos" e que "essa ação requer planejamento e diretrizes norteadoras para o atendimento integral da criança em seus aspectos físico, psicológico, intelectual e social..., com garantia de qualidade". Assim, uma proposta de ensino de nove anos que não dê conta do atendimento integral, com qualidade, poderá colocar crianças na escola, mas acabar por antecipar o fracasso escolar por não atender adequadamente as suas necessidades, uma vez que se operam mudanças na lei, mas a criança de seis anos continua sendo a mesma com relação ao que é específico dessa faixa etária.

Em 2008, o Ministério da Educação publicou orientações relativas aos três primeiros anos do ensino fundamental. O documento especifica que "o antigo terceiro período da Pré-Escola não pode se confundir com o primeiro ano do Ensino Fundamental" (Ministério da Educação, 2008, p. 5). O primeiro ano no ensino fundamental de nove anos é parte integrante de um ciclo de três anos de duração, chamado de ciclo da infância (Ministério da Educação, 2008).

O documento especifica que o agrupamento de crianças de seis, sete e oito anos deve respeitar, rigorosamente, a faixa etária, considerando as diferenças individuais e de desenvolvimento. No entanto, não traz com clareza quais 
são as adequações necessárias para que sejam respeitadas as necessidades de cada faixa etária e de cada indivíduo.

Quando analisado na prática o que foi regulamentado por lei, autores como Lugle e Aguiar (2009) constataram, junto a professores regentes do primeiro ano, uma evidente preocupação em "dar conta" do conteúdo em si e não tanto uma preocupação pautada em conciliar aprendizagem e necessidades específicas do desenvolvimento da criança. Assim, as autoras concluíram que os docentes necessitam olhar para essas crianças como crianças e não permitir que seja encurtada essa fase tão significativa de aprendizagens e descobertas, privilegiando os conteúdos.

Em relação à idade de ingresso no primeiro ano do EF, após enfrentar demandas judiciais, o Estado do Paraná no ano de 2007 passou a admitir o ingresso de crianças com cinco anos, desde que fossem levados em conta os seguintes requisitos: a) termo de responsabilidade pela antecipação da matrícula da criança, assinado pelos pais ou responsáveis; b) explicitação no Regimento Escolar; c) proposta pedagógica adequada ao desenvolvimento dos alunos; d) comprovação da existência de vagas no estabelecimento de ensino (Deliberação CEE/PR n 02/2007, 2007).

Desse modo, embora a legislação brasileira determine o ingresso aos seis anos de idade completos até 31 de março, e apesar dessas ressalvas, a maioria dos municípios do estado do Paraná assumiu a matrícula de crianças que completam seis anos para muito além da data de corte, ou seja, a qualquer tempo no ano de ingresso. Tal prática se deve a ações como a do Ministério Público do estado que ajuizou Ação Civil Pública (Autos n 402/2007 - 1 ${ }^{\text {a }}$ Vara da Fazenda Pública de Curitiba) para assegurar o direito das crianças com menos de seis anos completos a se matricularem nas escolas públicas, sendo emitida liminar em 07 de março de 2007, deferindo o pedido e assegurando aos pais este direito (Autos $n^{\circ} 402 / 2007,2007$ ).

Dessa forma, de acordo com Gnoatto e Bogo (2008, p. 09), “... um cenário dispare vem se configurando no contexto das salas de aulas, formado pela presença de crianças com diferentes percursos em termos de acesso à Educação Infantil (EI) e mesmo referente à idade". As autoras concluem que, mesmo que esses elementos não impeçam a aprendizagem, acabam por interferir nas condições de trabalho do professor ou educador.

Na mesma direção, a Assembleia Legislativa do Estado do Paraná aprovou a Lei $n^{\circ} 16.049$, de 19 de fevereiro de 2009 , conferindo o direito à matrícula no primeiro ano do ensino fundamental às crianças que completem seis anos até a data de 31 de dezembro do ano letivo: "Art. $1^{\circ}$ Terá direito à matrícula no $1^{\circ}$ ano do Ensino Fundamental de Nove Anos, a criança que completar seis anos de idade até o dia 31 de dezembro do ano em curso" (Lei n 16.049, 2009).

No início do ano de 2010, data limite para a implantação do ensino fundamental de nove anos, conforme determinado pela Lei $n^{\circ} 11.274 / 2006$, e com o objetivo de definir com exatidão a data de corte para a matrícula no primeiro ano do ensino fundamental, o Conselho Nacional de Educação aprovou a Resolução n 1, de 14 de janeiro de 2010 , definindo a data de corte como 31 de março para a matrícula no primeiro ano do ensino fundamental de nove anos (Resolução CNE/CEB 1/2010, 2010). Posteriormente, a Resolução $n^{\circ} 06$ art. $3^{\circ}$, de 20 de outubro de 2010 reiterou essa determinação proibindo a matrícula de crianças com idade inferior a seis anos na data de corte (Resolução CNE/ CEB 6/2010, 2010).

No entanto, estando em plena vigência a liminar concedida na Ação Civil Pública n 402/2007 e também em plena vigência a Lei Estadual no 16.049/2009, ambas do Estado do Paraná, o poder público ficou obrigado a efetuar a matrícula, sem impor quaisquer condições ou restrições, nem mesmo a justificativa de inexistência de vagas.

Tendo em vista que as crianças com idade inferior a seis anos na data de corte poderiam ter sua matrícula antecipada mediante avaliações psicológicas, em dezembro de 2014 o Conselho Federal de Psicologia (CFP) emitiu um parecer, a pedido do Conselho Nacional de Educação (CNE),no qual se manifesta contrário à condicionalidade da avaliação psicológica para o ingresso da criança menor de seis anos no Ensino Fundamental. De acordo com o parecer, o Conselho Federal de Psicologia "posiciona-se de forma favorável ao corte etário e de forma desfavorável à condicionalidade da avaliação psicológica para a matrícula de crianças fora do corte etário para o ensino fundamental e educação infantil" (CFP, 2014).

Dessa forma, reafirma-se que cada uma das etapas da educação brasileira possui uma organização específica fundamentada cientificamente e ancorada em concepções do desenvolvimento da aprendizagem. Assim, teóricos como Piaget, Vygotsky e Wallon, apesar de partirem de pressupostos e questionamentos diferentes, são citados no documento por apresentarem algumas concordâncias no que diz respeito ao desenvolvimento infantil. Desse modo, independentemente dos referenciais teóricos, por volta de 6/7 anos de idade ocorre uma mudança significativa no desenvolvimento da criança e que se caracteriza como um momento de transição (CFP, 2015).

O parecer discute ainda a importância da atuação do psicólogo junto à escola, para que possa compreender a totalidade das questões e não apenas parte delas. E no que se refere à avaliação psicológica especifica-se que: "Se consideramos as características da criança de 5 anos de idade, conforme sucintamente apresentadas, é extremamente preocupante a sua submissão a processos avaliativos que implicarão, em última instância, decisões sobre sua 'progressão' em relação ao nível de ensino"(CFP, 2015).

Em 27 de janeiro de 2015, a $4^{a}$ Turma do Tribunal Regional Federal da $4^{\text {a }}$ Região (que compreende os estados do Rio Grande do Sul, Santa Catarina e Paraná) negou, por unanimidade, provimento aos embargos da declaração do Ministério Público Federal, decidindo que havendo previsão em lei, não há ilegalidade em resoluções que fixam diretrizes operacionais relativas ao corte etário (Apelação/Reexame Necessário $n^{\circ}$ 5000600-25.2013.404.7115, 2015). As resoluções possuem caráter nacional e devem ser aplicadas em todos os estados e municípios da Federação, de modo a uni- 
formizar o ingresso na educação básica. Assim, pressupõe-se que haverá nova adequação no estado do Paraná e em outros estados brasileiros, quanto à idade de ingresso das crianças no primeiro ano do ensino fundamental.

Considerando a importância de se discutir o tema, o presente artigo tem por objetivo revisar publicações brasileiras que tratam do primeiro ano do ensino fundamental de nove anos, de modo a identificar os principais temas dessas publicações, as conclusões e orientações propostas pelos autores. Espera-se contribuir com reflexões sobre essa importante etapa escolar, considerando que uma compreensão adequada dos objetivos do primeiro ano do ensino fundamental, bem como das necessidades da criança nesse período do desenvolvimento, contribuirá para uma prática escolar mais efetiva e um resultado em termos de satisfação com a escola, especialmente para os seus destinatários.

\section{Método}

De modo a desenvolver o estudo, foram revisadas publicações brasileiras que tratam do tema do primeiro ano do ensino fundamental de nove anos. Como fonte de pesquisa, primeiramente, utilizou-se a base de dados do SciELO, sendo a busca realizada em novembro de 2015 e compreendendo as publicações do período de 2005 a novembro de 2015. Foram utilizados os seguintes termos de busca: Ensino Fundamental de Nove Anos (resultando em 43 publicações, dos quais nove foram selecionados para compor a análise) e Primeiro Ano do Ensino Fundamental (resultando em cinco artigos, os quais se repetiam aos resultados da busca anterior).

A seleção dos artigos foi realizada a partir da leitura do resumo das publicações, o que permitiu identificar se os mesmos de fato tratavam do tema de interesse. Posteriormente foi realizada uma pesquisa na base de dados do Portal de Periódicos da Capes em novembro de 2015, compreendendo publicações brasileiras do mesmo período da busca anterior. Foram utilizados como termos de busca: Ensino Fundamental de Nove Anos (resultando em 37 artigos revisados por pares dos quais sete foram selecionados para compor a análise por tratarem do tema em estudo. Os demais, ou não tratavam especificamente do tema ou já haviam sido selecionados na busca da base de dados do SciELO) e Primeiro Ano do Ensino Fundamental (resultou em seis artigos, sendo que um não estabelecia relação com o tema e os outros cinco se sobrepunham aos da pesquisa anterior).

A análise dos dados por categorias temáticas foi realizada pelo método de Análise de Conteúdo (Bardin, 1979), considerando as seguintes etapas: a) leitura e discussão de cada artigo, buscando identificar características gerais e especificidades; b) exploração e codificação, por meio da classificação do conteúdo em unidades de análise independentes, as quais partiram da própria estrutura do artigo; c) agrupamento das unidades em categorias analíticas estabelecidas a posteriori.

Após a leitura dos artigos, os dados foram classificados em uma tabela objetivando explorar particularidades das publicações, importantes para atender ao objetivo deste estudo, tais como, autor/ano, tema central, objetivos, metodologia, resultados e discussões/conclusões. Posteriormente, os dados sistematizados foram reagrupados em três categorias temáticas, para então serem discutidos e interpretados à luz das orientações propostas pelos documentos oficiais sobre o ensino fundamental de nove anos, como leis e decretos no âmbito federal e estadual, e demais materiais de divulgação científica.

\section{Resultados e Discussão}

A primeira categoria trata do tema das políticas educacionais, conforme Tabela 1. A análise revelou que, apesar de a nova política ter sido proposta com o objetivo de propiciar maiores oportunidades para as crianças de classes inferiores, ela carece de um caminho bem traçado, causando desconforto e incerteza nos profissionais da educação. Segundo Gontijo (2013), as proposições do MEC partem do pressuposto da carência cultural de maneira que as orientações para a alfabetização dessas crianças estão fundamentadas na aquisição de capacidades que viriam a suprir essa carência.

Autores como Durli e Schneider (2015) discutiram sobre o fato de que os professores e as escolas não foram previamente preparados para receber as crianças que passaram a entrar mais cedo no EF. Além disso, pontuaram que, apesar de existirem algumas orientações, pouco ou nada mudou na formação continuada dos profissionais, que ainda não estariam entendendo com clareza o que deve mudar em sua prática pedagógica.

Nesse sentido, Silva e Portilho (2013), apontaram que muitas crianças de seis anos são submetidas a um regime de trabalho escolar incompatível com a sua faixa etária e a práticas pedagógicas que não valorizam as tentativas de produção e não contribuem para que aconteça a aprendizagem. O documento do governo brasileiro sobre o ensino fundamental de nove anos (Ministério da Educação, 2008), salientou a importância da construção de uma proposta pedagógica que corresponda às necessidades específicas da infância.

Relativo ao surgimento da política educacional, para Chaguri e Jung (2013), a inclusão da criança mais cedo na escola consiste em uma importante conquista, especialmente para as classes populares. O Brasil, ao longo da sua história, promoveu grande desigualdade na distribuição de renda e poder, viabilizando infâncias distintas para classes sociais distintas (Nascimento, 2007). Durante muito tempo, crianças de classes abastadas foram educadas por preceptores particulares enquanto os filhos dos pobres, desde bem pequenos, eram vistos como força produtiva e, assim, não se priorizava a educação. Assim, a busca pela democratização da escolarização obrigatória é muito recente (Nascimento, 2007).

No que diz respeito à política, a ampliação do EF visa incluir no sistema educacional uma parcela significativa de crianças que até então se encontrava fora da escola. Além disso, a política aponta que a maioria das crianças que 
Tabela 1. Categoria Temática: Política Educacional.

\begin{tabular}{|c|c|c|}
\hline Autores (Ano) & Objetivo & Principais resultados e conclusões \\
\hline Oliveira e Guimarães (2013) & $\begin{array}{l}\text { Demonstrar como tem sido construída } \\
\text { a política de inclusão fazendo a } \\
\text { contextualização do momento histórico } \\
\text { brasileiro. }\end{array}$ & $\begin{array}{l}\text { Os documentos emitidos pelo MEC apresentam dados } \\
\text { para comprovar e convencer de que a maioria dos } \\
\text { estados brasileiros já em } 2003 \text { tinha as condições } \\
\text { necessárias para ampliação do EF. Essa política se } \\
\text { origina num momento de intensos discursos a respeito } \\
\text { da proteção da infância e a preocupação em escolarizar } \\
\text { as crianças cada vez mais cedo. }\end{array}$ \\
\hline Gontijo (2013) & $\begin{array}{l}\text { Compreender as orientações formuladas } \\
\text { pelo MEC para o EF de nove anos no } \\
\text { que se refere à alfabetização, procurando } \\
\text { analisar as políticas de alfabetização } \\
\text { implementadas entre } 2003 \text { e } 2012 \text {. }\end{array}$ & $\begin{array}{l}\text { As proposições do MEC partem da ideia de carência } \\
\text { cultural e dessa forma, as orientações para o ensino da } \\
\text { escrita se fundamentam em processos de aquisição de } \\
\text { capacidades que visam suprir essas carências. }\end{array}$ \\
\hline $\begin{array}{l}\text { Chaguri e } \\
\text { Jung (2013) }\end{array}$ & $\begin{array}{l}\text { Possibilitar a discussão a respeito da } \\
\text { política de ampliação do EF e verificar as } \\
\text { ações educacionais previstas em termos } \\
\text { de leitura e escrita dentro desse novo } \\
\text { cenário educacional. }\end{array}$ & $\begin{array}{l}\text { Conclui-se que essa ampliação da escolarização } \\
\text { obrigatória é uma conquista para as classes populares, } \\
\text { e que precisa ser defendida, mas que ainda não tem um } \\
\text { caminho bem traçado. }\end{array}$ \\
\hline Durli e Schneider (2015) & $\begin{array}{l}\text { Refletir sobre a necessidade de revisão } \\
\text { dos currículos escolares no contexto de } \\
\text { ampliação do EF. }\end{array}$ & $\begin{array}{l}\text { No bojo dessa política esteve também a discussão sobre } \\
\text { a necessidade de adequação dos currículos escolares, a } \\
\text { fim de contemplar um ano a mais de EF, porém, nenhum } \\
\text { dos estados da região sul apresentou de forma objetiva } \\
\text { uma proposta curricular para a rede, sendo que foi } \\
\text { atribuída essa tarefa às escolas ou sistemas municipais } \\
\text { (no caso do Paraná). Os professores, a quem se atribuiu } \\
\text { a responsabilidade de protagonizar uma ampla reforma } \\
\text { curricular, não foram devidamente preparados. }\end{array}$ \\
\hline Silva e Portilho (2013) & $\begin{array}{l}\text { Analisar a percepção e atuação dos } \\
\text { professores sobre a ampliação do EF de } \\
\text { nove anos. }\end{array}$ & $\begin{array}{l}\text { Muitas atividades vão na contramão ao que é proposto } \\
\text { nos documentos oficiais, pois não promovem a tomada } \\
\text { de consciência e a busca de estratégias pelo aluno, que } \\
\text { valorizem as tentativas de produções, enfim, práticas que } \\
\text { contribuam para que aconteça a aprendizagem. }\end{array}$ \\
\hline
\end{tabular}

Nota. Sistematização de dados da literatura realizada pelos autores.

ingressam em instituições escolares antes dos sete anos apresenta melhores resultados que aquelas que ingressam aos sete anos (Ministério da Educação, 2009).

Autores como Oliveira e Guimarães (2013) discutiram que essa inclusão tem origem no momento em que se discute intensamente sobre a proteção da infância e sobre a preocupação de escolarizar a criança cada vez mais cedo. As autoras questionaram o porquê de não tornar a pré-escola obrigatória ao invés de ampliar o EF, e respondem apontando que os investimentos na Educação Infantil (EI) sempre foram um ponto crítico. Assim, a ampliação do ensino fundamental teria sido uma estratégia de fazer um único investimento sem maiores gastos por parte da administração pública.
O documento que orienta sobre os três primeiros anos do ensino fundamental de nove anos admite que é necessário repensar o EF como um todo e não apenas o primeiro ano. Destaca que a EI não tem como objetivo preparar a criança para o ensino fundamental, pois a mesma possui objetivos próprios (Ministério da Educação, 2008).

A segunda categoria de análise trata do tema da implantação do ensino fundamental de nove anos, conforme Tabela 2. 
Tabela 2. Categoria Temática: Implantação do Ensino Fundamental de Nove Anos.

\begin{tabular}{|c|c|c|}
\hline Autores (Ano) & Objetivo & Principais resultados e conclusões \\
\hline Santos e Vieira (2006) & $\begin{array}{l}\text { Mostrar como foi implantado o EF de } \\
9 \text { anos em Minas Gerais e identificar } \\
\text { que condições possibilitaram sua } \\
\text { emergência e as consequências de sua } \\
\text { implementação. }\end{array}$ & $\begin{array}{l}\text { Além dos problemas de infraestrutura, de currículo e da } \\
\text { formação docente, a interpretação dos dispositivos legais } \\
\text { não foi unívoca entre os professores. }\end{array}$ \\
\hline Pansini e Marin (2011) & $\begin{array}{l}\text { Investigar em que condições ocorreu } \\
\text { a implantação do EF de } 9 \text { anos em um } \\
\text { município de Rondônia. }\end{array}$ & $\begin{array}{l}\text { A implantação desta política, nas escolas investigadas, } \\
\text { ocorreu de forma inesperada, sem qualquer preparação } \\
\text { prévia seja em aspectos estruturais, adaptações } \\
\text { curriculares ou formação para a comunidade escolar. }\end{array}$ \\
\hline $\begin{array}{l}\text { Arelaro, Jacomini e Klein } \\
\text { (2011) }\end{array}$ & $\begin{array}{l}\text { Analisar o processo de implementação } \\
\text { do ingresso de crianças de } 6 \text { anos nas } \\
\text { escolas de São Paulo, analisando as } \\
\text { mudanças ocorridas na dinâmica das } \\
\text { escolas com a implantação das leis. }\end{array}$ & $\begin{array}{l}\text { A partir de } 2006 \text { o número de reprovações nas séries } \\
\text { iniciais aumentou de forma expressiva. Foi constatado } \\
\text { que nenhuma mudança significativa aconteceu em termos } \\
\text { de formação dos profissionais, o que descaracteriza a } \\
\text { proposta e compromete a qualidade do ensino. }\end{array}$ \\
\hline Correa (2011) & $\begin{array}{l}\text { Estudar o processo de implantação do } \\
\text { primeiro ano de nove anos do EF na rede } \\
\text { municipal de São Paulo e seus impactos } \\
\text { sobre a El. }\end{array}$ & $\begin{array}{l}\text { Atuais políticas públicas priorizam os investimentos } \\
\text { no EF, porém não aumenta significativamente o seu } \\
\text { montante e ainda desconsideram a realidade das escolas } \\
\text { sem prepará-las para as mudanças. A autora observou } \\
\text { que na El as atividades mecânicas como a cópia de letras } \\
\text { e números, estaria ocorrendo de forma mais intensa sob } \\
\text { o pretexto de que uma preparação para o EF é agora, } \\
\text { ainda mais necessária. }\end{array}$ \\
\hline
\end{tabular}

\begin{tabular}{lll}
\hline & Apontar as adaptações estruturais & Houve a aquisição de equipamentos e mobiliários novos \\
& realizadas na escola e as mudanças & para as escolas e foram introduzidas novas práticas \\
nas práticas institucionais; Analisar os & no cotidiano. Existe a crença de que a ampliação do \\
& motivos que levaram à antecipação do & tempo de permanência é um indicador de qualidade da \\
& ingresso das crianças no EF, bem como, & educação brasileira. \\
& as perdas e ganhos para as crianças. & \\
\hline
\end{tabular}

Nota. Sistematização de dados da literatura realizada pelos autores

Autores como Santos e Vieira (2006) analisaram a implantação do EF de nove anos em Minas Gerais, identificando as condições que possibilitaram a sua emergência e as consequências da sua implementação. Além dos problemas de infraestrutura, de currículo e da formação docente, os autores constataram que a interpretação dos dispositivos legais não foi unívoca entre os professores.

Por sua vez, Pansini e Marin (2011) investigaram em que condições ocorreu a implantação do EF de nove anos em um município de Rondônia. A implantação dessa política, nas escolas investigadas, ocorreu de forma inesperada, sem qualquer preparação prévia seja em aspectos estruturais, adaptações curriculares ou formação para a comunidade escolar.

Na mesma direção, Correa (2011) observou que as reformas que vêm ocorrendo na educação básica estão focadas no EF. No entanto, isso não significou um aumento dos recursos destinados a este e sim uma restrição ainda maior para com as outras etapas da educação básica, como a educação infantil. Somando-se a isso, as reformas teriam sido implantadas sem considerar a realidade das escolas brasileiras.

Ainda relativo às reformas, Correa (2011) apontou o impacto que a política trouxe para a El, principalmente, pelo fato de que os profissionais desta etapa da educação básica terem ficado à margem da reorganização do ensino no contexto analisado. Além disso, a cópia mecânica de letras e números estaria acontecendo com mais intensidade, sob o pretexto de melhor preparar as crianças para o EF. Desse modo, para esse autor, cabe repensar uma política que integre $\mathrm{El}$ e EF, de modo a tratar as diferentes etapas do desenvolvimento com o mesmo cuidado.

Do mesmo modo, Almeida (2011) problematizou que a política, que ampliou o tempo de permanência obrigatório da criança na escola, tem sido apresentada como um indicador de qualidade do ensino, o que não pode ser tomado como verdade absoluta. Destacou que as velhas práticas continuam nas escolas e, muitas vezes, de forma 
desarmônica com as novas orientações instaladas a partir do ingresso das crianças pequenas.

Por sua vez, Arelaro, Jacomini e Klein (2011) discutiram a falta de clareza da nova política, bem como, a escassez de informações aos profissionais da educação, o que descaracteriza a proposta e acaba por comprometer a qualidade do ensino. As autoras também apontaram que, a partir de 2006, o número de reprovações nas séries iniciais aumentou de forma expressiva.

A terceira categoria trata do tema da alfabetização e do letramento. Para Tasca e Pinto (2013), a alfabetização pode ser compreendida como o processo pelo qual a criança aprende técnicas para dominar o código escrito. Já, o letramento, refere-se ao uso social da escrita.
Autores como Neves, Castanheira e Gouvêa (2015), acompanharam a passagem de uma turma de Educação Infantil para o EF, a fim de entender como ocorre o processo de socialização e aprendizagem nesses dois momentos da educação básica. $\mathrm{Na} \mathrm{EI}$, o letramento possui estreita ligação com a brincadeira, enquanto que no uso da linguagem escrita há relações de poder. Assim, a criança ao participar de atividades percebe que a linguagem escrita confere ao adulto um saber que o coloca num lugar de poder, lugar esse almejado pela criança.

Por sua vez, Albuquerque, Morais e Ferreira (2008) discutiram sobre a distância existente entre aqueles que pensam as políticas educacionais e aqueles que as põem em prática, configurando-se assim como um grande obstá-

Tabela 3. Categoria Temática: Alfabetização e Letramento.

\section{Autores (Ano)}

Objetivos

\section{Principais resultados e conclusões}

Na dinâmica da sala de aula as professoras recriam as

Analisar como tem se caracterizado as práticas de alfabetização na rede municipal da cidade do Recife, tomando como eixo de sala de aula pelo professor alfabetizador.

Através da análise curricular, discute a Kishimoto, Pinazza, Morgado e proposta de uma prática educativa onde Toyofuki (2011) jogo e letramento sejam aliados no $1^{\circ}$ ano da Escola de Aplicação da USP. investigação a "fabricação" do cotidiano da

orientações oficiais. O desconhecimento do cotidiano da sala de aula e do perfil dos professores alfabetizadores por parte dos que geram prescrições constituem um obstáculo para a efetivação de inovações viáveis, que permitam alfabetizar com êxito e garantam a iniciação das crianças no mundo da cultura escrita.

Os dados indicam que o currículo implementado na EAFEUSP atende as necessidades das crianças, ajustase as concepções de atividade, mediações e uso de jogos imaginários com apoio de signos e artefatos. Lembrando que nem todas as escolas têm condições de oferecer tais atividades.

Atividades que envolvem brincadeiras e a família são aliadas

Pensar sobre como as crianças se alfabetizam aos seis anos, tratando de discutir a produção de crianças leitoras e produtoras de texto.

Fomentar uma discussão, a partir das inquietações de professores referentes às suas práticas alfabetizadoras, no processo de implementação do EF de 9 anos.

no processo de alfabetização. Os professores precisam "ir além das cartilhas", trazendo atividades variadas para as crianças e os pais devem ajudar no processo aproximando o filho do mundo da leitura.

As professoras mencionam táticas usadas por elas em sala de aula para ensinar as crianças diante das novas demandas procurando superar os desafios. No que se refere à alfabetização e letramento, a ampliação das práticas exige um trabalho sistematizado, sendo que a alfabetização é se apropriar do código escrito e o letramento é se apropriar dos variados usos da escrita.

Analisar como ocorreu o processo de socialização e aprendizagem dos alunos na El e no EF; Conhecer o processo de alfabetização e letramento e o papel do brincar nesse processo.

Apresentar os resultados de uma pesquisa realizada em 2010, no município de Pelotas (RS), sobre as práticas pedagógicas utilizadas em sala de aula.
É importante que haja articulação entre letramento e brincadeira. Identificou-se que no uso da linguagem escrita existem relações de poder, onde a criança percebe que o domínio da escrita confere certo lugar de poder ao adulto, que é almejado pela criança.

Indicaram que a alfabetização desenvolvida no cotidiano da sala de aula está em descompasso com a proposta do governo federal e municipal. Segundo os autores, infelizmente, ainda não se estabeleceu um caminho claro do que a escola deve fazer.

Nota. Sistematização de dados da literatura realizada pelos autores. 
culo na efetivação de inovações viáveis para alfabetizar com êxito e sem atropelar a infância. Assim, segundo os autores, é no dia-a-dia da sala de aula que as professoras recriam as orientações oficiais, adaptando-as à realidade em que estão inseridas.

Por sua vez, autores como Nogueira e Peres (2013) apontaram o descompasso entre a política educacional e a prática pedagógica, bem como a falta de clareza sobre o que é adequado ao primeiro ano. Nesse sentido, ainda não estaria estabelecido um caminho claro do que a escola deve fazer.

Na mesma direção, Dornelles (2011) discutiu o fato de que o professor deve ir além das cartilhas, diferenciando as atividades, apontando também para a importância dos pais ou cuidadores no processo de alfabetização e letramento da criança. Quanto mais esta for exposta às experiências do uso da leitura, melhor se dará esse processo. A autora identificou que o desejo dos pais seria o de que seus filhos ficassem mais tempo sob os cuidados da escola, pois, a escolarização representava para eles uma chance de ascensão social.

Por outro lado, o trabalho de Kishimoto, Pinazza, Morgado e Toyofuki (2011), apontou aspectos positivos na implantação do primeiro ano do EF, que aconteceu na Escola de Aplicação da USP, a EAFEUSP. Os dados indicaram que havendo de fato adequação da escola às necessidades da criança, torna-se possível incluir a criança de seis anos no ensino fundamental, sem prejuízo ao que é próprio da infância, como por exemplo, o espaço para o brincar.

\section{Considerações finais}

Neste trabalho, foi abordado o ingresso da criança de seis anos no EF, bem como as particularidades desta faixa etária. Feitas as análises dos dados, constatou-se que existe um distanciamento entre a política educacional e a prática pedagógica, o que se revela um fato preocupante. Conclui-se que muito já se progrediu em relação aos cuidados com a infância, mas que muito ainda deve ser debatido e aperfeiçoado. Por outro lado, práticas que deram certo configuram-se em um dado relevante, apontando que é possível sim incluir a criança cada vez mais cedo, respeitando as suas necessidades, e propondo atividades condizentes com o seu desenvolvimento.

A partir dos dados das publicações, pode-se questionar quais seriam as melhores adaptações curriculares, qual o papel da escola na atualidade e como anda a relação entre as crianças e a escola. Como se pode constatar, não é apenas o aumento do tempo na escola que vai garantir um melhor aprendizado. Assim, a qualidade do tempo de permanência na escola precisa ser empregada de forma eficaz, fazendo com que a criança aprenda de forma divertida e prazerosa, além da necessidade de uma adaptação do espaço físico, dos materiais didáticos e equipamentos.

A escola é também um importante agente de apoio às famílias, principalmente àquelas pertencentes às classes com maiores dificuldades financeiras, no que diz respei- to aos cuidados com a criança. Nas classes populares, a maioria dos pais/responsáveis possui longas jornadas de trabalho e não têm onde deixar os filhos que muitas vezes ficam sozinhos em casa ou sob os cuidados dos irmãos mais velhos. No entanto, quando a escola assume um caráter de "depósito de crianças", ou um local apenas de assistência, ela perde o seu objetivo principal que é o de possibilitar a todos o acesso ao conhecimento científico.

A partir disso, pode-se concluir que a inclusão da criança de seis anos no ensino fundamental configurou-se num passo muito importante para a democratização do ensino e - que quando associada à boa formação dos professores, a um quadro de funcionários satisfatório, ambiente adequado para o atendimento dessas crianças e com material didático e mobiliário compatível com as necessidades desses alunos - se mostra uma grande possibilidade de propiciar maiores oportunidades às crianças que até, então, estavam fora da escola.

\section{Referências}

Albuquerque, E. B. C., Morais. A. G., \& Ferreira, A. T. B.(2008). As práticas cotidianas de alfabetização: $O$ que fazem as professoras? Revista Brasileira de Educação, 13(38), 252-264.

Almeida, J. R. (2011). Ensino fundamental de nove anos: Ampliação da permanência e qualidade de ensino. EccoS Revista Científica, $25,159-179$.

Apelação/Reexame Necessário $n^{\circ}$ 5000600-25.2013.404.7115/RS (2015). Ação civil pública. Ensino. Resolução $n^{\circ} 1$ e resolução $n^{\circ}$ 6. Conselho nacional de educação. Corte etário para matrícula no ensino infantil e ensino fundamental. Ausência de ofensa ao princípio da isonomia. Porto Alegre, RS: Tribunal Regional Federal da $4^{a}$ Região. Recuperado: 05 ago. 2017. Disponível: https://trf-4.jusbrasil. com.br/jurisprudencia/423011265/apelacao-reexame-necessarioapelreex-50006002520134047115-rs-5000600-2520134047115/ inteiro-teor-423011351? ref=juris-tabs.

Arelaro, L. R. G., Jacomini, M. A., \& Klein, S. B. (2011). O ensino fundamental de nove anos e o direito à educação. Educação e Pesquisa, 37(1), 35-51.

Ariès, P. (1978). A história social da criança e da família. Rio de Janeiro: Francisco Alves.

Autos $n^{\circ} 402 / 2007$ (2007). Ação Civil Pública - 1ª. Vara da Fazenda Pública de Curitiba. Curitiba: Poder Judiciário do Estado do Paraná. Disponível: http://www.mppr.mp.br/arquivos/File/ DECISAOMERITO_3110.pdf

Bardin, L. (1979). Análise de conteúdo (L. A. Reto \& A. Pinheiro, Trad.) São Paulo: Edições 70. (Trabalho original publicado em 1977).

Benjamin, W. (1984). Reflexões: A criança, o brinquedo, a educação. São Paulo: Summus. 
Chaguri, J. P.\& Jung, N. M. (2013). Letramento no ensino fundamental de nove anos no Brasil: Ações legais e pedagógicas previstas nos documentos oficiais. Educação e Pesquisa, 39(4), 927-942.

Conselho Federal de Psicologia. (2015). Parecer sobre o corte etário no ensino fundamental. Brasília: Comissão de Psicologia na Educação do Conselho Federal de Psicologia (CFP). Disponível: http://site.cfp.org.br/cfp-divulga-parecer-contrarioa-condicionalidade-da-avaliacao-psicologica-para-ingresso-demenores-de-seis-anos-no-ensino-fundamental/

Correa, B. C. (2011). Educação infantil e ensino fundamental: desafios e desencontros na implantação de uma nova política. Educação e Pesquisa, 37(1), 105-120.

Deliberação CEE/PR n 02/2007 (2007, 13 de abril). Altera o artigo 12 da Deliberação $n^{\circ}$ 03/06-CEE. Curitiba: Conselho Estadual de Educação. Recuperado: 05 ago. 2017. Disponível: http:// celepar7cta.pr.gov.br/seed/deliberacoes.nsf/7b2a997ca37239c30 32569ed005fb978/332dfe76130e267f832572c000426f88?OpenD ocument

Dornelles, L. V. (2011). Os alfabetizados-desviantes ou sobre a educação dos 6 anos. Educação e Pesquisa,37(1), 141-155.

Durli, Z. \& Schneider, M. P. (2015). Ampliação do ensino fundamental na região sul do Brasil: pontos e contrapontos da proposta curricular. Educação em Revista, 31(01), 223-247.

Gnoatto, E. \& Bogo, L. V. (2009). O ensino fundamental de nove anos no estado do Paraná: Dos fundamentos legais às práticas pedagógicas, um (per)curso sinuoso.Em I Simpósio Nacional de Educação, XX Semana da Pedagogia. Universidade Estadual do Oeste do Paraná, Cascavel: PR. Recuperado: 05 ago. 2017. Disponível: http://www.unioeste.br/cursos/cascavel/pedagogia/ eventos/2008/5/Artigo\%2024.pdf.

Gontijo, C. M. M. (2013). Alfabetização no ciclo inicial do ensino fundamental de nove anos: reflexões sobre as proposições do ministério da educação. Cadernos Cedes, 33(89), 35-49.

Kishimoto, T. M., Pinazza, M. A., Morgado, R. F. C., \&Toyofuki, K. R. (2011). Jogo e letramento: Crianças de 6 anos no ensino fundamental. Educação e Pesquisa, 37(01), 191-210.

Kramer, S. (2007). A infância e sua singularidade. Em J. Beauchamp, S. D. Pagel, A. R. do Nascimento (Orgs.), Ensino Fundamental de nove anos: Orientações para a inclusão da criança de seis anos (pp. 13-23). Brasília: Ministério da Educação, Secretaria de Educação Básica.

Lei $n^{\circ}$ 10.172, de 9 de Janeiro de 2001 (2001). Aprova o Plano Nacional de Educação (PNE). Brasília: Presidência da República. Recuperado: 05 ago. 2017. Disponível: http://www.planalto.gov. br/ccivil_03/leis/leis_2001/10172.htm

Lei $n^{\circ} 11.274$ (2006, 6 de fevereiro de 2006.) Altera a redação dos arts.
29, 30, 32 e 87 da Lei no 9.394, de 20 de dezembro de 1996, que estabelece as diretrizes e bases da educação nacional, dispondo sobre a duração de 9 (nove) anos para o ensino fundamental, com matrícula obrigatória a partir dos 6 (seis) anos de idade. Brasília: Presidência da República. Recuperado: 05 ago. 2017. Disponível: http://www.planalto.gov.br/ccivil_03/_Ato2004-2006/2006/Lei/ L11274.htm

Lei $n^{\circ}$ 16.049, de 19 de fevereiro de 2009 (2009, 19 de fevereiro). Dispõe que terá direito à matrícula no $1^{\circ}$. Ano do Ensino Fundamental de Nove Anos, a criança que completar 6 anos até o dia 31 de dezembro do ano em curso. Curitiba, PR: Palácio do Governo. Recuperado: 05 ago. 2017. Disponível: http://www.alep. pr.gov.br/sc_integras/leis/LEIO000016049.html.

Lugle, A. M. C. \& Aguiar, B. C. L. (2009). Um olhar investigativo sobre a concepção de infância no primeiro ano do Ensino Fundamental de nove anos. Em IX Congresso Nacional de Educação (Educere), III Encontro Sul Brasileiro de Psicopedagogia. Pontifícia Universidade Católica do Paraná, Curitiba. Curitiba: PUCPR. Recuperado: 05 ago. 2017. Disponível: http://www.pucpr.br/eventos/educere/ educere2009/anais/pdf/2504_1224.pdf.

Ministério da Educação (2008). Orientação sobre os três anos iniciais do Ensino Fundamental de nove anos. Salvador: Ministério da Educação. Recuperado: 05 ago. 2017. Disponível: http://portal. mec.gov.br/cne/arquivos/pdf/2008/pceb004_08.

Ministério da Educação (2009). A criança de 6 anos a linguagem escrita e Ensino Fundamental de nove anos. Brasília: Ministério da Educação. Recuperado: 05 ago. 2015. Disponível: http:// portal.mec.gov.br/index.php?option=com_docman\&task=doc_ download\&gid=4034\&ltemid .

Ministério da Educação \&Fundo Nacional de Desenvolvimento da Educação (2004). Ensino Fundamental de nove anos: orientações gerais. Brasília: Ministério da Educação/Fundo Nacional de Desenvolvimento da Educação. Recuperado: 18 mai. 2015. Disponível: http://portal.mec.gov.br/seb/arquivos/pdf/9anosgeral.pdf.

Nascimento, A. M. (2007). A infância na escola e na vida: Uma relação fundamental. Em J. Beauchamp, S. D. Pagel, A. R. do Nascimento (Orgs.), Ensino Fundamental de nove anos: Orientações para a inclusão da criança de seis anos (pp. 25-32). Brasília: Ministério da Educação, Secretaria de Educação Básica.

Neves, V. F. A, Castanheira, M. L, \& Gouvêa, M. C. S. (2015). O letramento e o brincar em processos de socialização na educação infantil. Revista Brasileira de Educação, 20(60), 215-244.

Nogueira, G. M. \& Peres, E. T. (2013). A supremacia da perspectiva associacionista em práticas alfabetizadoras no $1^{\circ}$ ano do ensino fundamental. Educação em Revista, 29(02), 65-89.

Oliveira, D. R. \& Guimarães, C. M. (2013). Constituição da política do ensino fundamental de nove anos. Acta Scientiarum, 35(2), 223233. 
Pansini, F. \& Marin, A. P. (2011). O ingresso de crianças de 6 anos no ensino fundamental: uma pesquisa em Rondônia. Educação e Pesquisa, 37(01), 87-103.

Postman, N. (1999). O desaparecimento da infância. São Paulo: Graphia.

Resolução CNE/CEB 1/2010 (2010, 14 de janeiro). Define Diretrizes Operacionais para a implantação do Ensino Fundamental de 9 (nove) anos. Brasília: Conselho Nacional de educação. Recuperado: 05 ago. 2017. Disponível: http://portal.mec.gov.br/ index.php?option=com_docman\&view=download\&alias=15541rceb001-10-pdf\&category_slug=abril-2014-pdf\&ltemid=30192

Resolução CNE/CEB 6/2010 (2010, 20 de outubro). Define Diretrizes Operacionais para a matrícula no Ensino Fundamental e na Educação Infantil. Brasília: Conselho Nacional de educação. Recuperado: 05 ago. 2017. Disponível: http://portal.mec.gov.br/ index.php?option=com_docman\&view=download\&alias=15249rceb00610\&Itemid $=30192$
Santos, L. L. C. P. \& Vieira, L. M. (2006). "Agora seu filho entra mais cedo na escola": a criança de seis anos no ensino fundamental de nove anos em Minas Gerais. Educação \& Sociedade, 27(96), 775-796.

Silva, T. F. \& Portilho, E. M. L. (2013). Os aspectos metodológicos da prática pedagógica no $1^{\circ}$ ano do ensino fundamental. Revista Ensaio: Avaliação e Políticas Públicas em Educação, 21(80),473496.

Szymanski, M. L. S. \& Bastos, C. C. B. (2011). O curso de Pedagogia da UNIOESTE - campus de Cascavel: História de suas reestruturações curriculares. Educere et Educare, 6, 217-232.

Szymanski, M. L. S., Bastos, C. C. B. C., Kliemann, M. P., \& Favero, E. (2014). A pesquisa como subsídio para avaliação curricular: Expectativa discente sobre o curso de pedagogia da UNIOESTE - Campus de Cascavel. Educere et Educare, 9(18), 755 - 763.

Tasca, D. S. O. \& Pinto, A. L. G. (2013). A divulgação do conceito de letramento e o contexto da escola de nove anos: o que dizem as professoras alfabetizadoras?Cadernos Cedes, 33(90),257-276.

Recebido em: 26/04/2016 Aprovado em: 30/01/2017

\section{Sobre os autores}

Eveline Fávero (evelinefavero@yahoo.com.br)

Doutorado em Psicologia pela Universidade Federal do Rio Grande do Sul, (2012), Professora Adjunta da Universidade Estadual do Oeste do Paraná

Dhyovana Guerra (dhyovanaguerra@hotmail.com)

Discente do curso de Pedagogia da Universidade Estadual do Oeste do Paraná.

Heder Luiz Matias Mendes dos Santos (hederhot@hotmail.com)

Graduação em Licenciatura em Letras Português/Espanhol pela União Educacional do Médio Oeste Paranaense, discente do curso de Pedagogia da Universidade Estadual do Oeste do Paraná.

Camila Molon Delazeri (camila.delazeri@hotmail.com)

Discente do curso de Pedagogia da Universidade Estadual do Oeste do Paraná. 